\title{
Distinguish functional hypothalamic amenorrhea and 1solated GnRH deficiency: A case report and review of the literature
}

\author{
${\text { Mehmet Sipahi }{ }^{* *} \text { and Vehbi Yavuz Tokgoz }}^{1}$ \\ Obstetrics and Gynecology Department, Giresun University, Giresun, Turkey
}

\begin{abstract}
A 24-year-old patient admitted to clinic because of secondary amenorrhea which persists for 5 years. She was misdiagnosed as Isolated Gonadotropin-releasing Hormone (GnRH) deficiency (IGD). However she had functional hypothalamic amenorrhea (FHA). Functional Hypothalamic Amenorrhea (FHA) is characterized by absence of menstrual cycles for longer than 6 months without any endocrine/systemic causal factors. FHA is a diagnosis of exclusion. Isolated Gonadotropinreleasing Hormone (GnRH) deficiency (IGD) is characterized with hypogonadism and low serum concentrations of the gonadotropins LH (luteinizing hormone) and FSH (follicle-stimulating hormone) which can be seen any age of life. Hypogonadism and incomplete sexual maturation can be detect on physical examination at adolescents and adults. Causes of secondary amenorrhea can be confused to evaluate sometimes, so accurate medical history and physical investigation is necessary for true diagnosis.
\end{abstract}

\section{Introduction}

Functional Hypothalamic Amenorrhea (FHA) is characterized by absence of menstrual cycles for longer than 6 months without any endocrine/systemic causal factors. FHA is mainly associated with stress factors such as psychological, physical or metabolic. Severe stresseses such as dieting, heavy training, or intense emotional events with or without body weight loss induces FHA. Consequently, FHA is a diagnosis of exclusion. A good anamnestic investigation including menarche, menstruel cycle pattern, time and duration of amenorrhea is necessary for diagnosis. Other causes of amenorhea (endocrine, metabolic and systemic diseases) should be excluded. IGD is characterized with hypogonadism and low serum concentrations of the gonadotropins LH and FSH. Approximately $60 \%$ of IGD is associated with Kallman Syndrome (KS [impaired sense of smell]) and \%40 is associated with normal sense of smell. Hypogonadism and incomplete sexual maturation can be detect on physical examination at adolescents and adults who have IGD.

\section{Case report}

A 24-year-old patient admitted to clinic with a 5-year history of secondary amenorrhea. Menarche occured at 12 years of age. She had irregular menses about 40 days with 7 days of menstruel flow. Polycystic ovary syndrome diagnosed at 14 years of age when she was admitted to a gynecologist because of irregular menses. Then she began to develop regular cycles with Oral Contraceptive Pills (OCP's) for 5 years. She gave up using OCS's after begining to university at a different city at 19 years of age. She develop a less regular pattern of menstruel bleeding for 1-2 months and then mensturation entirely stopped. She admitted to gynecologist again with secondary amenorrhea. She had been reported a normal body mass index with normal diet and there was no acute weight gain or loss. She did not participate in any stringent physical exercise. She denied headaches, galactorrhea, visual symptomps, hirsutism, acne, thin skin and edema. She was normotensive and thyroid functions were normal. Tanner stage was 5 for pubic hair and breast development. The pelvic ultrasound examination revealed a normal uterus and ovaries. No free fluid or pelvic mass were seen. Magnetic resonance imaging of the sella showed a normal pituitary gland, normal cerebellum and cavernous sinuses. Laboratory investigations revealed low FSH $(0,15 \mathrm{mIU} / \mathrm{mL}$; normal range, $2,5-$ $10,2 \mathrm{mIU} / \mathrm{mL})$, low $\mathrm{LH}(1,24 \mathrm{mIU} / \mathrm{mL}$; normal range, $1,9-12,5 \mathrm{mIU} /$ $\mathrm{mL})$, normal Estradiol $\left(\mathrm{E}_{2}\right)(23,7 \mathrm{pg} / \mathrm{mL}$; normal $<160 \mathrm{pg} / \mathrm{mL})$, normal prolactin $(14,1 \mathrm{ng} / \mathrm{mL}$; normal range $1,9-25 \mathrm{ng} / \mathrm{mL})$ and normal total testosterone ( $<20 \mathrm{ng} / \mathrm{mL}$; normal, $<81 \mathrm{ng} / \mathrm{mL}$ ). She was misdiagnosed as IGD with these findings and OCP's adviced for regular mensturation pattern. But she denied taking OCP's and admitted to our clinic after graduating from the university with a period of 5 years amenorrhea. Pregnancy test was negative. On ultrasound examination uterus was normal in diameter with $5 \mathrm{~mm}$ endometrial thickness. Bilateral ovaries visualized with normal antral follicle counts ( 6 at right ovary, 5 at left ovary). $35 \mu \mathrm{g}$ ethynil estradiol and $2 \mathrm{mg}$ cyproterone acetate started for 21 days. She admitted to clinic on the third day of menstruel bleeding after 25 days. Laboratory investigations revealed normal FSH, LH, $\mathrm{E}_{2}$, prolactin, TSH, $\mathrm{T}_{4}$, cortisol, DHEA-S and glucose. Renal and hepatic functions and lipid tests were also normal. Tests have proven to be correct by repeating the same day in a different laboratory. Patient recalled to clinic without using any drugs one month later. She had a return of regular menstrual bleeding after this time of period.

Correspondence to: Mehmet Sipahi, Department of Obstetrics and Gynecology, Giresun University, Nizamiye Mahallesi, Mumcular Sokak, 1/1 28000 Giresun, Turkey, Tel: +905304141232, E-mail: mehmetsipahi@hotmail.com

Key words: Amenorrhea, Hypothalamic, Gonadotropin, Deficiency, Mensturation

Received: September 10, 2017; Accepted: October 09, 2017; Published: October 12,2017 


\section{Discussion}

Diagnosis of secondary amenorrhea was not challenging for this patient. Her clinical presentation with grade 5 Tanner staging and normal pelvic ultrasound with normal $\mathrm{FSH}, \mathrm{LH}$ and $\mathrm{E}_{2}$ was exclude many causes of secondary amenorrhea. IGD usually exists with primary amenorrhea, hypogonadism, incomplete sexual maturation and impaired function of smell. She had normal menstruel bleeding after OCP and normal gonadotropin levels. Spontanoues mensturations began after OCP and there was no need for more investigations. FHA was the only disgnosis for this patient after excluding other causes.

Reversible inhibition of the hypothalamic-pituitary-ovarian axis causes FHA. The overall prevalence of functional hypothalamic amenorrhea among all amenorrhea disorders ranges from $15 \%$ to $48 \%$ [1]. It is not a result of a structural abnormality or organic disease, mainly related to various stress factors. FHA may occur at any age of life [2]. FHA can be classified into the three groups: a)Various stress factors b) rapid weight loss, and c) extreme physical exercises. Psychological stressors such as emotional, familial and working problems can induce amenorrhea by reducing food intake [3]. Psychological stressors can disrupt hypothalamus-pituitary activity which controls the ovarian functions [4]. These cascades affect Gonadotropin Releasing Hormone $(\mathrm{GnRH})$ secretion negatively via neuromodulators produced in the central nervous system. Emotional, cultural, cognitive and social factors may become major stressor agents when acute changes ocur. Consequently, failure of the reproductive function is reversible and become normal when reproduction is considered essential for those women.

Adrenocorticotropin Hormone (ACTH) and cortisol levels are elevated due to response of stressors and activates lipolysis and glycogenolysis. Injection of Corticotropin-Releasing Hormone (CRF) intraventricularly reduces $\mathrm{GnRH}$ and Luteinizing Hormone (LH) release in animals [5]. Central $\beta$-endorphin ( $\beta \mathrm{EP})$ levels increase as a result of $\mathrm{CRH}$ levels which is a potent inhibitor of $\mathrm{GnRH}$ and LH secretion. Patients with high levels of basal cortisolemia have poor response to ACTH stimulation [6]. There are some neurosteroids for modulation of CNS. These are; pregnenolone, pregnenolone sulfate, allopregnanolone, dehydroepiandrosterone and dehydroepiandrosterone sulfate [7].

FHA is charecterized by reduced LH plasma levels as a result of stress-induced endogenous opioid hypertone. FSH plasma levels are typically results to be normal. However there are two possible situations for LH levels: normogonadotropinism ( $\mathrm{LH}$ more than $3 \mathrm{mU} / \mathrm{mL}$ ) and hypogonadotropinism (LH equal or less than $3 \mathrm{mU} / \mathrm{mL}$ ).

IGD is partial or complete absence of GnRH-mediated release of LH and FSH while anterior pituitary anatomy and function is normal. A recent epidemiological study showed the incidence of Kallman Syndrome 1:30,000 in males and 1:125,000 in females [8]. 15 genes detected abnormal for nearly half of all IGD's. Other gene mutations for the remaining cases of IGD are unknown. Prenatal testing for pregnancies is also possible if the genetic pathologies are known in the family.

FHA is a diagnosis of exclusion. A good anamnestic investigation is necessary for diagnosis. Menarche, menstruel cycle properties, time and duration of amenorrhea has to be asked. Other causes of amenorhea (endocrine, metabolic and systemic diseases) should be excluded. Any stress situation induced by family or working problems, weight loss, eating disorders, physical training or activity should be asked to patient. Weight and body composition and body mass index should be noted. Other causes of amenorrhea such as hyperandrogenemia, hyperprolactinemia, hypoproteinemia need to be excluded. Hormonal profile especially LH, FSH, estradiol, androgens, cortisol, prolactin, thyroid hormones, thyroid autoantibodies and biochemical profile must also be evaluated. In some cases, additional tests are needed like the pulsatility study of $\mathrm{LH}$ and FSH, the GnRH test and the naloxone test for diagnosis.

Physical examination of genital organs, laboratory and imaging findings and sense of smell are necessary for diagnosis of IGD. Tanner staging should be used to detect incomplete sexual maturation. On laboratory, low or normal serum concentration of $\mathrm{LH}$ and $\mathrm{FSH}$ with low concentrations of sex steroids are evaluate. Other anterior pituitary hormones are typically normal. If Kallmann Syndrome (KS) is present, aplasia or hypoplasia of the olfactory tracts can be determined. Otherwise hypothalamus and pituitary evaluated normal on MRI examination. Pathogenic variants in KAL1 cause KS and pathogenic variants in KISS1, KISS1R (GPR54), TAC3, TACR3, GNRHR, and GNRH1 cause normosmic (nIGD). Major findings of IGD are delay in breast development and primary amenorrhea but sometimes spontaneous menses can be seen. Adrenal glands may be sufficient to produce androgens for normal onset of pubic hair growth (adrenarche). Most patients with IGD have eunuchoid body habitus because of inadequate sex hormones which causes failure in bone growth plates.

Other causes of impaired gonadotropin secretion are; central nervous system or pituitary tumors, brain/pituitary radiation, pitiutary apoplexy, head trauma, Cushing's disease, some drugs, chronic systemic illness, eating disorders, malnutrition, thyroid disorders, diabetes mellitus, sarcoidosis, hemochromatosis and histiocytosis. Syndromes such as, CHARGE, Prader-Willi, Bardet-Biedl and leptin deficiency/resistance also causes impaired gonadotropin secretion.

If eating disorders are present, the quality of food have to be increased with more proteins. Psychological support might be also suggested. Opioid receptor blocker (naltrexone cloridrate) administration might be suggested for reversing opioidergic hypertone. Acetyl-L-Carnitine (ALC) is an another alternative treatment which modulates HPG axis function in hypogonadotropinemic patient [9]. Gamma-aminobutyric acid (GABA) is another important modulator of stress or anxiety in central nervous system. It has been shown that, there is a rapid decrease in GABA levels as a response to acute stress [10].

Initial treatment at IGD for optimal breast devolepment should consist of only estrogen treatment via oral or topical preparations. Progestins should be added after optimal breast development obtained for endometrial protection. Pulsatile GnRH stimulation and exogenous gonadotropins are FDA approved treatments for fertility desired women. In vitro fertilization is also an option.

While investigating the causes of secondary amenorrhea, the history of patient should be asked in detail. Physiologic causes of amenorrhea like pregnancy, menopause and lactation should be ruled out firstly and physical examination should be perform in detail. Pelvic ultrasound examination is essential to exclude ovarian and uterine pathologies such as ovarian cysts and tumors. Laboratory findings are helpful for diagnosis. All of these steps are esssential for accurate diagnosis.

\section{Acknowledgements}

We did not have any any financial support and we declare that we do not have any conflicts of interest. 


\section{References}

1. Liu JH, Bill AH (2008) Stress-associated or functional hypothalamic amenorrhea in the adolescent. Ann N Y Acad Sci 1135: 179-184. [Crossref]

2. Genazzani AD (2005) Neuroendocrine aspects of amenorrhea related to stress. Pediatr Endocrinol Rev 2: 661-668. [Crossref]

3. Cameron JL, Helmreich DL, Schreihofer DA (1993) Modulation of reproductive hormone secretion by nutritional intake: stress signals versus metabolic signals. Hum Reprod 8:162-167. [Crossref]

4. Facchinetti F, Fava M, Fioroni L, Genazzani AD, Genazzani AR (1993) Stressful life events and affective disorders inhibit pulsatile LH secretion in hypothalamic amenorrhea. Psychoneuroendocrinology 18: 397-404. [Crossref]

5. Petraglia F, Sutton S, Vale W, Plotsky O (1987) Corticotropin-releasing factor decrease plasma luteinizing hormone levels in female rats by inhibiting gonadotropin-releasing hormone release into hypophyseal portal circulation. Endocrinology 120: 1083-1088. [Crossref]
6. Nappi RE, Petraglia F, Genazzani AD, D'Ambrogio G, Zara C, et al. (1993) Hypothalamic amenorrhea: evidence for a central derangement of hypothalamicpituitary-adrenal cortex axis activity. Fertil Steril 59: 571-576. [Crossref]

7. Robel P1, Baulieu EE (1995) Neurosteroids: biosynthesis and function. Crit Rev Neurobiol 9: 383-394. [Crossref]

8. Laitinen EM, Vaaralahti K, Tommiska J, Eklund E, Tervaniemi M, et al. (2011) Incidence, phenotypic features and molecular genetics of Kallmann syndrome in Finland. Orphanet J Rare Dis 6: 41. [Crossref]

9. Onofrj M, Bodis-Wollner I, Pola P, Calvani M (1983) Central cholinergic effects of levo-acetyl-carnitine. Drugs Exp Clin Res 9: 161-167.

10. Nuss P1 (2015) Anxiety disorders and GABA neurotransmission: a disturbance of modulation. Neuropsychiatr Dis Treat 11: 165-175. [Crossref]

Copyright: (2017 Sipahi M. This is an open-access article distributed under the terms of the Creative Commons Attribution License, which permits unrestricted use, distribution, and reproduction in any medium, provided the original author and source are credited. 